\title{
Hepatitis B virus infection is associated with gastric cancer in China: an endemic area of both diseases
}

\author{
X-L Wei ${ }^{1,3}$, M-Z Qiu ${ }^{1,3}$, Y Jin ${ }^{1,3}$, Y-X Huang ${ }^{2}$, R-Y Wang ${ }^{2}$, W-W Chen ${ }^{1}$, D-S Wang ${ }^{1}$, F Wang ${ }^{1}$, H-Y Luo ${ }^{1}$, \\ D-S Zhang ${ }^{1,3}, \mathrm{~F}-\mathrm{H}$ Wang ${ }^{1}, \mathrm{Y}-\mathrm{H} \mathrm{Li}{ }^{1}$ and $\mathrm{R}-\mathrm{H} \mathrm{Xu}^{*, 1}$ \\ ${ }^{1}$ Department of Medical Oncology, Sun Yat-sen University Cancer Center, State Key Laboratory of Oncology in South China, \\ Collaborative Innovation Center for Cancer Medicine, 651 Dongfeng Road East, Guangzhou 510060, China and ${ }^{2} Z$ Zhongshan \\ School of Medicine, Sun Yat-sen University, Guangzhou 510080, China
}

Background: Hepatitis B virus (HBV) infection was demonstrated to be a risk factor of several cancers of the digestive system. In addition, liver cirrhosis, which could possibly result from chronic HBV infection, was associated with a higher risk of gastric cancer. However, the association of HBV infection and gastric cancer has not been investigated.

Methods: A retrospective case-control study with 580 cases and 580 controls matched for age, sex and year of diagnosis was conducted. The associations between gastric cancer and HBV infection were explored with univariate and multivariate unconditional logistic regression analysis.

Results: Hepatitis B surface antigen (HBsAg) was positively associated with gastric cancer (AOR (95\% Cl): 1.49 (1.06-2.10)). This association remained significant in patients without family history of gastric cancer ( $A O R(95 \% \mathrm{Cl})$ : (1.06-2.11)). For HBsAg-negative population, being anti-HBc positive/anti-HBs negative, which possibly indicated occult HBV infection, was also found to have some associations with gastric cancer. In addition, some synergistic effects between HBV infection and blood type A in gastric cancer were identified.

Conclusions: The HBV infection was positively related with gastric cancer, especially for patients without family history of gastric cancer. Further prospective studies are warranted to confirm this relationship.

Gastric cancer (GC) is one of the most common malignant diseases in the digestive system, contributing to $\sim 10 \%$ of annual deaths from cancer. Although the incidence of GC has been declined for several decades, it is still the fourth most common cancer in men and fifth in women (Jemal et al, 2011). Several risk factors have been explored. The most thoroughly investigated and commonly recognised factor is the infection of Helicobacter pylori ( $\mathrm{Hp})$ (Correa et al, 1990; Niwa et al, 2010). Other factors including family history of GC (Yaghoobi et al, 2010), genetic factors (Gonzalez et al, 2002; Loh et al, 2009), excessive salt intake (Peleteiro et al, 2011), alcohol drinking (Tramacere et al, 2012), smoking (Ladeiras-Lopes et al, 2008) diabetes mellitus (Yoon et al, 2013) and blood type A (Wang et al, 2012) are also quite convincing, whereas the role of Epstein-Barr virus (EBV) infection (Kim et al, 2009; Yuan et al, 2013) as well as lack of fruits and vegetables consumption (Norat et al, 2014) is controversial. Beyond these, opium is also proposed to be a risk factor for gastric adenocarcinoma recently (Shakeri et al, 2013; Sadjadi et al, 2014).

The prevalence of hepatitis B virus (HBV) infection varies largely worldwide. The relatively high prevalence areas are located in some developing countries, including China (Dehesa-Violante

\footnotetext{
*Correspondence: Dr R-H Xu; E-mail: xurh@sysucc.org.cn

${ }^{3}$ These authors contributed equally to this work.
} 
and Nunez-Nateras, 2007). The HBV infection was once a major health burden in China, but the prevalence rate has dropped steadily from no less than $8 \%$ to $2-7 \%$ in recent years since the application of universal infant immunisation policy (Lu et al, 2010). Hepatitis B virus is considered to be a hepatotrophic virus, and it has long been confirmed to be the most important risk factor for hepatocellular carcinoma ( $\mathrm{Yu}$ et al, 1990). However, several studies have probed the existence of HBV in some extrahepatic organs and tissues, such as the kidneys, skin, lymph nodes, bone marrow, vessel walls, colon, pancreas as well as stomach (Dejean et al, 1984; Mason et al, 1993; Chen et al, 2004). Moreover, it has been put forward that HBV infection is also a risk factor for nonHodgkin's lymphoma (Engels et al, 2010) and pancreatic cancer (Hassan et al, 2008).

In a study by Chen et al (2004), the coexistence of Hepatitis B surface antigen ( $\mathrm{HBsAg}$ ) and hepatitis B core antigen ( $\mathrm{HBcAg}$ ) with $\mathrm{Hp}$ immunoglobulin $\mathrm{G}$ antigen in gastric antrum mucosa was observed in patients with chronic HBV infection or HBV-related cirrhosis. In addition, they found that there was no difference in the rates of $\mathrm{HBV}$ antigen expression between the $\mathrm{Hp}$ - positive and -negative patients. It was also found that patients with liver cirrhosis had a high prevalence of gastric ulcers (Kirchner et al, 2011) and an increased risk of GC (Zullo et al, 2003). Besides, the impact of $\mathrm{Hp}$ on gastric ulcers in patients with liver cirrhosis was found to be relatively weak (Kirchner et al, 2011). It is well known that $\mathrm{HBV}$ infection is the most important risk factor for liver cirrhosis in China. We therefore speculate that HBV infection may play a role in the risk of GC in China, as China is an endemic region for both GC and $\mathrm{HBV}$ infection. However, the markers of either past or present $\mathrm{HBV}$ infection could possibly be also frequently detectable in patients with GC. The relation between HBV infection and GC might be a casual association. Thus, we launched this case-control study to investigate the associations of HBV infection with GC.

\section{MATERIALS AND METHODS}

Ethics statement. All patients provided written informed consent for their information to be stored and used in the hospital database. Study approval was obtained from independent ethics committees at Cancer Center of Sun Yat-sen University. The study was undertaken in accordance with the ethical standards of the World Medical Association Declaration of Helsinki.

Study population. There were 725 patients potentially diagnosed with GC from 1 September 2007 to 31 December 2009 at Sun Yatsen University Cancer Center in Guangzhou, China. Patients pathologically diagnosed with other types of cancer such as gastric neuroendocrine tumour, gastric stromal tumour and gastric mucosa-associated lymphoid tissue lymphoma were excluded. We also eliminated those without available blood test results for HBV infection. Finally, there were 652 patients confirmed to be diagnosed with GC qualified to be considered for the cases. The prevalence of $\mathrm{HBV}$ infection differed from time to time, and with the adoption of universal infant immunisation policy, the difference had become more apparent in recent years. Thus, we aimed to establish a control group matched with the GC group not only in age and sex, but also in the year of diagnosis. During the same period, there were 977 patients pathologically confirmed with nonmalignant diseases and with available blood test results for HBV infection, including 556 males and 421 females. All of them had received surgical treatment in our hospital, and the diagnoses were histopathologically confirmed to be nonmalignant diseases, including parotid adenolymphoma, benign meningioma, benign adrenal adenoma and so on. The list of pathologic diagnoses of the nonmalignant diseases is shown in Supplementary Table 1.
None of these diseases had been reported to have any association with $\mathrm{HBV}$ infection. Patients with a recorded history of malignant diseases were excluded. However, there were not enough male patients for the controls to build a $1: 1$ case-control study if we were to include all 652 eligible patients in the cases, especially for the older patients ( $>60$ years old). We randomly selected 580 patients from the qualified candidates for both the cases and controls to generate a 1:1 case-control study, with the balance of age, sex and year of diagnosis considered (Table 1). Baseline characteristics, blood test results for HBV infection and risk factors for GC were retrospectively collected from medical records. Family history of GC (no/yes), ABO blood type (A/B/AB/O), history of chronic gastritis (no/yes), smoking (never/past and/or current), alcohol consumption (never/past and/or current), diabetes mellitus (no/yes) and hepatitis C virus (HCV) infection (no/yes) were collected for both the cases and controls. Information on $\mathrm{Hp}$ infection (negative/positive) was available only for partial cases $(42.6 \%, n=247)$. There was no information on Hp infection for the controls. In addition, history of chronic gastritis was only defined by medical history, and the results of gastroscopy and pathologic findings were not taken into consideration. This was because most controls did not receive a gastroscope inspection.

Serologic assay for $\mathrm{HBV}$ infection. For every patient in our hospital, a blood test for HBV infection was encompassed in routine examinations at the first visit. Blood samples were collected for the separation of serum samples that were used for the test of $\mathrm{HBV}$ infection. Several HBV-related antibodies and antigens were tested, including $\mathrm{HBsAg}$, antibody to hepatitis B surface antigen (anti-HBs), hepatitis B e antigen ( $\mathrm{HBeAg}$ ), antibody to hepatitis B e antigen (anti-HBe) and antibody to hepatitis $\mathrm{B}$ core antigen (anti-HBc). Enzyme-linked immunosorbent assay was applied for this test. We had specific workers responsible for sending blood samples for tests in time to guarantee the quality of the test. Besides, qualified positive and negative control serum provided by the Ministry of Health of the People's Republic of China was used in this test to ensure the accuracy of the test.

Clinical significance of $\mathrm{HBV}$-related antibodies and antigens. HBsAg: the serum maker for current HBV infection, including chronic hepatitis B and inactive HBsAg carrier state. Anti-HBs: a protective antibody in $\mathrm{HBV}$ infection. Anti-HBs positive indicates the acquisition of immune for HBV infection, and such a state may result from both current or prior $\mathrm{HBV}$ infection and hepatitis $\mathrm{B}$ vaccination. $\mathrm{HBeAg}$ : $\mathrm{HBeAg}$ positive indicates a high level of $\mathrm{HBV}$ DNA $\left(200000-2\right.$ billion $\left.\mathrm{IU} \mathrm{ml}^{-1}\right)$ in initial phase of $\mathrm{HBV}$ infection. However, in chronic hepatitis B, a portion of patients

\begin{tabular}{|c|c|c|c|}
\hline Characteristic & $\begin{array}{c}\text { Gastric cancer } \\
\text { group }(n=580) \\
\text { No. }(\%)\end{array}$ & $\begin{array}{l}\text { Control group } \\
\qquad(n=580) \\
\text { No. }(\%)\end{array}$ & $P$-value \\
\hline Age (years) & & & 0.77 \\
\hline$<50$ & $144(24.8)$ & $134(23.1)$ & \\
\hline $50-60$ & 207 (35.7) & 215 (37.1) & \\
\hline$>60$ & $229(39.5)$ & $231(39.8)$ & \\
\hline Sex & & & 0.61 \\
\hline Male & 406 (70.0) & $398(68.6)$ & \\
\hline Female & $174(30.0)$ & $182(31.4)$ & \\
\hline Year of diagnosis & & & 0.13 \\
\hline 2007 & $80(13.8)$ & 80 (13.8) & \\
\hline 2008 & $236(40.7)$ & 204 (35.2) & \\
\hline 2009 & $264(45.5)$ & $296(51.0)$ & \\
\hline
\end{tabular}


were found to be $\mathrm{HBeAg}$ negative with a lower level of HBV DNA (2000-20 million IU ml ${ }^{-1}$ ). Anti-HBe: appearance of anti-HBe after clearance of $\mathrm{HBeAg}$ represents immune activation, and combined with $\mathrm{HBsAg}$ positive indicates inactive $\mathrm{HBsAg}$ carrier state. Anti-HBc: a serum marker for current or prior HBV infection. The clinical value of HBV-related antibodies and antigens were referenced to the American Association for the Study of Liver Diseases (AASLD) Practice Guideline: Chronic Hepatitis B: Update 2009.

Test for $\mathrm{Hp}$ infection. The rapid urease test was applied for the measurement of $\mathrm{Hp}$ infection. During gastroscopy, one biopsy specimen from the antrum and another from the corpus were obtained from each patient. The specimens were subjected to a rapid urease test to detect the presence of $\mathrm{Hp}$ urease. If the colour changed from yellow to pink within $24 \mathrm{~h}$ of incubation at room temperature, a positive result was reported. If the colour kept unchanged, the result was reported to be negative. In our retrospective collection, only $42.6 \%$ patients with GC had the test. According to the explanation of the staff members from the Department of Endoscopy, whether the test would be done or not depended on two main factors. One was the readiness of the patients, and the other was of the doctors. Some of them paid more attention to the biopsy for the diagnosis of GC whereas the test for Hp was ignored.

Statistical analysis. The statistical analyses were performed with SPSS 13.0 statistical software (SPSS Inc., Chicago, IL, USA). A twotailed $P$-value of $<0.05$ was considered statistically significant. Differences in baseline parameters (age, sex and year of diagnosis) between the cases and controls were evaluated by $\chi^{2}$ test. Binary logistic regression analysis was used to analyse the associations of GC and the characteristics of family history of GC, ABO blood type, history of chronic gastritis, smoking, alcohol consumption, diabetes mellitus, HCV infection, HBV antibodies and antigens. Variables significant in the univariate analyses and baseline characteristics including age, sex, and year of diagnosis were included for multivariate analyses. Multivariate logistic regression analysis was used to estimate the (AORs) and 95\% confidence interval (CI).

\section{RESULTS}

Basic characteristics of the cases and controls. A total of 580 cases were matched to 580 controls. The ratio of case-control was $1: 1$. As for the distribution of age, patients were classified into three groups: $<50$ years old, 50-60 years old and $>60$ years old. The number of patients classified into the three groups were 144 (24.8\%), $207(35.7 \%)$, and $229(39.5 \%)$ in the cases, and 134 (23.1\%), $215(37.1 \%)$ and $231(39.8 \%)$ in the controls respectively. A male predominance was found in the cases $(70.0 \%, n=406)$, and the matched controls had a similar distribution of sex with 398 (68.6\%) male patients. The numbers of patients diagnosed in 2007, 2008 and 2009 were 80 (13.8\%), $236(40.7 \%)$ and $264(45.5 \%)$ in the cases, and 80 (13.8\%), $204(35.2 \%)$ and $296(51.0 \%)$ in the controls respectively. The cases and controls were well matched in the distribution of age, sex and year of diagnosis $(P=0.77, P=0.61$ and $P=0.13$ respectively, Table 1 ).

The general study population. There were 41 (7.1\%) patients identified to have a family history of GC in the cases, whereas there were only $5(0.9 \%)$ such patients in the controls. The numbers of patients with a history of chronic gastritis were $76(13.1 \%)$ and 21 $(3.6 \%)$ in the cases and controls, respectively. The univariable logistic regression analyses showed that family history of GC and history of chronic gastritis were significantly associated with GC $(P<0.001$ and $P<0.001$, respectively). As for some other factors identified to increase risk of GC by some previous investigations, including smoking, alcohol consumption and history of diabetes, we did not find them to be associated with GC in this study (Table 2).

With regard to the HBV antibodies and antigens, there were 100 (17.2\%) HBsAg-positive patients in the cases, whereas the prevalence rate was significantly lower in the controls with 70 (12.1\%) HBsAg-positive patients (OR (95\% CI): 1.52 (1.09-2.11), Table 2). For anti-HBs-positive characteristic, there were 327 (56.4\%) and $364(62.8 \%)$ patients in the cases and controls, respectively (OR (95\% CI): 0.77 (0.61-0.97), Table 2). However, no differences were identified in the rates of HBeAg $(P=0.42)$, anti$\mathrm{HBe}(P=0.10)$ and anti-HBc $(P=0.26)$ in the univariate logistic regression analyses.

As suggested by the clinical value of anti-HBs, being anti-HBs positive might result from both $\mathrm{HBV}$ infection and hepatitis $\mathrm{B}$ vaccination. However, according to the literature, hepatitis $\mathrm{B}$ vaccination was adopted for newborns since 1992 in China, and therefore most of the patients included in our study presented with being anti-HBs positive resulting from current or prior $\mathrm{HBV}$ infection. In addition, being anti-HBs positive actually had different clinical significance in patients with current $\mathrm{HBV}$ infection (HBsAg positive) and without current $\mathrm{HBV}$ infection (HBsAg negative), which would be explained in detail in the discussion. Thus, to authentically evaluate the value of anti-HBs in GC, the research patients should not be analysed as a general population but should be classified into two subgroups. Subgroup 1: patients with current HBV infection (HBsAg positive). Subgroup 2: patients without current $\mathrm{HBV}$ infection (HBsAg negative), including patients with resolved hepatitis B or without confirmable history of HBV infection, and it should be clarified that this subgroup of patients is possibly exposed to $\mathrm{HBV}$ infection previously and might have occult $\mathrm{HBV}$ infection. As a result, there were $3(3.0 \%)$ and $1(1.4 \%)$ anti-HBs positive patients in the cases and controls, respectively, in patients with current $\mathrm{HBV}$ infection (HBsAg positive); the difference was not statistically significant by univariate logistic regression analysis (AOR (95\% CI): 2.13 (0.22-20.95)). In patients without current HBV infection (HBsAg negative), being anti-HBs positive was identified in 324 $(67.5 \%)$ and $363(71.2 \%)$ patients in the cases and controls, respectively; the difference was not significant either (AOR $(95 \%$ CI): $0.84(0.64-1.10))$. Thus, anti-HBs was found not to be associated with GC in this study (Table 2).

In the multivariate logistic regression analysis, the association of HBsAg with GC was not only adjusted by family history of GC (no/yes) and history of chronic gastritis (no/yes), which were found to be significantly associated with GC in the univariate logistic analysis, but also by age (as a continuous variable), sex (male/female) and year of diagnosis (2007/2008/2009), which were controlled artificially and kept to be potential confounding factors. Anti-HBs was not included for the reason explained above. After adjustment by confounding factors, the association between HBsAg and GC was still significant, with an estimated AOR (95\% CI) of 1.49 (1.06-2.10) (Table 3).

Subgroup analyses of patients without a family history of GC. Patients with and without family history of GC represented different populations with distinct genetic background, with genetic factors playing more important roles in the former, indicating the importance of HBsAg that might differ in the two subgroups. Thus, further analyses were conducted stratified by family history of GC (no/yes). The HBsAg was identified not to be related with GC in the subgroup with family history of GC $(P=0.67$, OR $(95 \% \mathrm{CI}): 1.66(0.17-16.38)$ in the univariate analysis). However, HBsAg was significantly related with GC in both univariate (OR (95\% CI): 1.43 (1.02-2.01)) and multivariate analysis (AOR (95\% CI): 1.49 (1.06-2.11)) in the subgroup without family history of GC (Supplementary Tables 2 and 3). 
Table 2. Associations of gastric cancer risk factors, hepatitis B virus antibodies and antigens with gastric cancer risk: univariate logistic regression analyses

\begin{tabular}{|c|c|c|c|c|c|}
\hline Variable & $\begin{array}{c}\text { Gastric cancer group }(n=580) \\
\text { No. }(\%)\end{array}$ & $\begin{array}{l}\text { Control group }(n=580) \\
\text { No. }(\%)\end{array}$ & OR & $95 \% \mathrm{Cl}$ & $P$-value \\
\hline Family history of gastric cancer (no/yes) & $539 / 41(92.9 / 7.1)$ & $575 / 5(99.1 / 0.9)$ & 8.75 & $3.43-22.30$ & $<0.001$ \\
\hline $\mathrm{ABO}$ blood group $(\mathrm{A} / \mathrm{B} / \mathrm{AB} / \mathrm{O})$ & & & & & 0.51 \\
\hline O & $221(39.0)$ & $245(42.2)$ & 1 & Reference & \\
\hline A & $166(29.3)$ & $148(25.5)$ & 1.24 & $0.93-1.66$ & 0.14 \\
\hline B & $142(25.0)$ & $146(25.2)$ & 1.07 & $0.80-1.45$ & 0.62 \\
\hline$A B$ & $38(6.7)$ & $36(6.2)$ & 1.17 & $0.72-1.91$ & 0.53 \\
\hline History of chronic gastritis (no/yes) & $504 / 76(86.9 / 13.1)$ & $559 / 21(96.4 / 3.6)$ & 4.01 & $2.44-6.60$ & $<0.001$ \\
\hline Smoking (never/past and/or current) & $365 / 211(63.4 / 36.6)$ & $359 / 222(61.7 / 38.3)$ & 0.93 & $0.74-1.18$ & 0.56 \\
\hline Alcohol consumption (never/past and/or current) & $477 / 99(82.8 / 17.2)$ & $487 / 93(84.0 / 16.0)$ & 1.09 & $0.80-1.48$ & 0.60 \\
\hline History of diabetes mellitus (no/yes) & $539 / 41(92.9 / 7.1)$ & $547 / 33(94.3 / 5.7)$ & 1.26 & $0.79-2.03$ & 0.34 \\
\hline HCV (negative/positive) & $538 / 2(99.6 / 0.4)$ & $539 / 3(99.4 / 0.6)$ & 0.67 & $0.11-4.01$ & 0.66 \\
\hline \multicolumn{6}{|l|}{ HBV } \\
\hline $\begin{array}{l}\text { HBsAg (negative/positive) } \\
\text { Anti-HBs (negative/positive) } \\
\text { HBeAg (negative/positive) } \\
\text { Anti-HBe (negative/positive) } \\
\text { Anti-HBc (negative/positive) }\end{array}$ & $\begin{array}{c}480 / 100(82.8 / 17.2) \\
253 / 327(43.6 / 56.4) \\
578 / 2(99.7 / 0.3) \\
380 / 200(65.5 / 34.5) \\
337 / 243(58.1 / 41.9)\end{array}$ & $\begin{array}{c}510 / 70(87.9 / 12.1) \\
216 / 364(37.2 / 62.8) \\
576 / 4(99.3 / 0.7) \\
406 / 174(70.0 / 30.0) \\
356 / 224(61.4 / 38.6)\end{array}$ & \begin{tabular}{|l|}
1.52 \\
0.77 \\
0.50 \\
1.23 \\
1.15 \\
\end{tabular} & $\begin{array}{l}1.09-2.11 \\
0.61-0.97 \\
0.09-2.73 \\
0.96-1.57 \\
0.91-1.45\end{array}$ & $\begin{array}{l}0.01 \\
0.03 \\
0.42 \\
0.10 \\
0.26\end{array}$ \\
\hline \multicolumn{6}{|l|}{ Subgroup 1} \\
\hline $\begin{array}{l}\text { Anti-HBs negative and } \mathrm{HBsAg} \text { positive } \\
\text { Anti-HBs positive and } \mathrm{HBsAg} \text { positive }\end{array}$ & $\begin{array}{c}97(97.0) \\
3(3.0)\end{array}$ & $\begin{array}{c}69(98.6) \\
1(1.4)\end{array}$ & \begin{tabular}{|l|}
1 \\
2.13
\end{tabular} & $\begin{array}{c}\text { Reference } \\
0.22-20.95\end{array}$ & 0.52 \\
\hline \multicolumn{6}{|l|}{ Subgroup 2} \\
\hline $\begin{array}{l}\text { Anti-HBs negative and } \mathrm{HBsAg} \text { negative } \\
\text { Anti-HBs positive and } \mathrm{HBsAg} \text { negative }\end{array}$ & $\begin{array}{l}156(32.5) \\
324(67.5)\end{array}$ & $\begin{array}{l}147(28.8) \\
363(71.2)\end{array}$ & \begin{tabular}{|l|l|}
1 \\
0.84
\end{tabular} & $\begin{array}{l}\text { Reference } \\
0.64-1.10\end{array}$ & 0.21 \\
\hline
\end{tabular}

Table 3. Association between HBsAg and gastric cancer adjusted by age, sex, year of diagnosis and risk factors in multivariate logistic regression analyses

\begin{tabular}{|l|c|c|c|}
\hline Variable & AOR & $95 \% ~ C l$ & $P$-value \\
\hline HBsAg (negative/positive) & 1.49 & $1.06-2.10$ & 0.02 \\
\hline Family history of gastric cancer (no/yes) & 8.61 & $3.36-22.08$ & $<0.001$ \\
\hline History of chronic gastritis (no/yes) & 4.04 & $2.44-6.68$ & $<0.001$ \\
\hline Sex (female/male) & 0.99 & $0.76-1.28$ & 0.93 \\
\hline Age (as a continuous variable) & 1.00 & $0.99-1.01$ & 0.54 \\
\hline Year of diagnosis (2007/2008/2009) & 0.93 & $0.78-1.10$ & 0.39 \\
\hline $\begin{array}{l}\text { Abbreviations: AOR=adjusted odds ratio; Cl= confidence interval; HBsAg= hepatitis B } \\
\text { surface antigen. }\end{array}$ \\
\hline
\end{tabular}

Subgroup analyses of HBsAg-negative patients. We subdivided HBsAg-negative patients into four subgroups according to the status of anti-HBc and anti-HBs. Univariate and multivariate logistic regression analyses were conducted. We found that compared with HBsAg-negative/anti-HBc-negative/anti-HBsnegative subgroup, HBsAg-negative/anti-HBc-positive/anti-HBsnegative subgroup had a trend of positive association with GC (AOR (95\% CI): 1.67 (0.997-2.80)). Compared with HBsAgnegative/anti-HBc-positive/anti-HBs-negative subgroup, the other three subgroups were statistically or had a trend to be negatively associated with GC (AORs (95\% CI): 0.62 (0.39-0.996), 0.47 (0.28$0.49), 0.60(0.36-1.003)$ ) (Tables 4 and 5). These associations became more apparent in HBsAg-negative patients without a family history of GC (Supplementary Table 4).

The synergetic effects of $\mathrm{HBV}$ infection and blood type $\mathrm{A}$. By subdividing patients into four subgroups according to ABO blood type (A/non-A) and HBsAg (negative/positive), it was found that compared with blood type non-A/HBsAg-negative population, blood type A/HBsAg-positive population was significantly and positively associated with GC (AOR (95\% CI): 2.41 (1.28-4.53)). We also subdivided the general population into another four subgroups according to $\mathrm{ABO}$ blood type (A/non-A) and anti-HBc (negative/positive). Similarly, compared with blood type non-A/ anti-HBc-negative population, blood type A/anti-HBc-positive population was significantly and positively associated with GC (AOR (95\% CI): $1.62(1.09-2.42)$ ) (Table 6).

\section{DISCUSSION}

This was the first case-control study to investigate the association between HBV infection and GC. Being HBsAg positive was identified unprecedented to be significantly and independently associated with GC, especially for patients without family history of GC. Occult HBV infection was also found to have some association 


\begin{tabular}{|c|c|c|c|c|c|}
\hline Variable & $\begin{array}{l}\text { Gastric cancer group } \\
\quad(n=480) \text { No. (\%) }\end{array}$ & $\begin{array}{l}\text { Control group } \\
(n=510) \text { No. }(\%)\end{array}$ & OR & $95 \% \mathrm{Cl}$ & $P$-value \\
\hline ABO blood group (A/B/AB/O) & & & & & 0.59 \\
\hline $\mathrm{O}$ & $189(40.3)$ & $214(42.3)$ & 1 & Reference & \\
\hline A & $135(28.8)$ & $132(26.1)$ & 1.16 & $0.85-1.58$ & 0.35 \\
\hline B & $112(23.9)$ & $131(25.9)$ & 0.97 & $0.70-1.33$ & 0.84 \\
\hline$A B$ & $33(7.0)$ & $29(5.7)$ & 1.29 & $0.75-2.20$ & 9.35 \\
\hline History of chronic gastritis (no/yes) & $414 / 66(86.3 / 13.8)$ & $491 / 19(96.3 / 3.7)$ & 4.12 & $2.43-6.98$ & $<0.001$ \\
\hline Family history of gastric cancer (no/yes) & $451 / 29(94.0 / 6.0)$ & $506 / 4(99.2 / 0.8)$ & 8.13 & $\begin{array}{l}2.84- \\
23.32\end{array}$ & $<0.001$ \\
\hline Smoking (never/past and/or current) & $311 / 166(65.2 / 34.8)$ & $317 / 193(62.2 / 37.8)$ & 0.88 & $0.68-1.14$ & 0.32 \\
\hline Alcohol consumption (never/past and/or current) & $397 / 80(83.2 / 16.8)$ & $430 / 80(84.3 / 15.7)$ & 1.08 & $0.77-1.52$ & 0.64 \\
\hline History of diabetes mellitus (no/yes) & $444 / 36(92.5 / 7.5)$ & $483 / 27(94.7 / 5.3)$ & 1.45 & $0.87-2.43$ & 0.16 \\
\hline HBsAg negative (A) & & & & & 0.12 \\
\hline $\mathrm{HBsAg}$ negative and anti-HBc negative and anti-HBs negative & $105(21.9)$ & $111(21.8)$ & 1 & Reference & \\
\hline $\mathrm{HBsAg}$ negative and anti-HBc negative and anti-HBs positive & $231(48.1)$ & $241(47.3)$ & 1.01 & $0.73-1.40$ & 0.93 \\
\hline $\mathrm{HBsAg}$ negative and anti-HBc positive and anti-HBs negative & $51(10.6)$ & $36(7.1)$ & 1.50 & $0.91-2.48$ & 0.12 \\
\hline $\mathrm{HBsAg}$ negative and anti-HBc positive and anti-HBs positive & $93(19.4)$ & $122(23.9)$ & 0.81 & $0.55-1.18$ & 0.27 \\
\hline HBsAg negative (B) & & & & & 0.12 \\
\hline $\mathrm{HBsAg}$ negative and anti-HBc positive and anti-HBs negative & $51(10.6)$ & $36(7.1)$ & 1 & Reference & \\
\hline $\mathrm{HBsAg}$ negative and anti-HBc negative and anti-HBs positive & $231(48.1)$ & $241(47.3)$ & 0.68 & $0.43-1.08$ & 0.10 \\
\hline $\mathrm{HBsAg}$ negative and anti-HBc positive and anti-HBs positive & $93(19.4)$ & $122(23.9)$ & 0.54 & $0.33-0.89$ & 0.02 \\
\hline $\mathrm{HBsAg}$ negative and anti-HBc negative and anti-HBs negative & $105(21.9)$ & $111(21.8)$ & 0.67 & $0.40-1.10$ & 0.12 \\
\hline
\end{tabular}

with GC. In addition, some synergistic effects between HBV infection and blood type A were identified.

Previous exploration has identified HBsAg as an independent risk factor for both liver cirrhosis and hepatocellular carcinoma (Lee et al, 2013a). Besides, liver cirrhosis has been reported to be a risk factor for gastric ulcer and GC (Zullo et al, 2003; Kirchner et al, 2011). Thus, the association of HBsAg with risk of GC may be linked by liver cirrhosis. It is possible that liver cirrhosis and/or HBV infection itself was responsible for increased risk of GC. On the other hand, HBV infection has been confirmed to be a risk factor for several cancers of other organs and tissues involved in HBV infection. Hepatocellular carcinoma is well known as one of the HBV-related cancers. As HBV infection also exists in gastric mucosa epithelial cells, it may be possible that HBV infection increases the risk of GC in a similar mechanism of HBV-related hepatocellular carcinoma. The HBV infection has been commonly recognised as a risk factor for hepatocellular carcinoma (Yu et al, 1990; Chen et al, 2006; Lee et al, 2013b). The mechanism of HBVinduced hepatocellular carcinoma has been thoroughly researched, and it is complex, including direct enhancement of chromosomal instability by integration of HBV DNA into the host genome that results in alterations of host gene expression and signalling pathways (Tan, 2011). Indirect mechanisms, such as persistent inflammation, oxidative stress, hypoxia caused by cirrhosis and sequential angiogenesis, are also raised up (Arzumanyan et al, 2013). Recently, the epigenetic changes generated by the HBVencoded X ( $\mathrm{HBx})$ protein became another focus in the exploration for mechanism of HBV-induced hepatocellular carcinoma (Tan, 2011; Tian et al, 2013). However, to understand the authentic and detailed mechanism of HBV infection-related GC, more studies should be conducted.
The simultaneous seropositivity of HBsAg and anti-HBs (which meant being anti-HBs positive in HBsAg-positive patients) was not common in HBV infection that was reported to be $<10 \%$ in the general population with HBV infection (Zhang et al, 2007; Liu et al, 2012; Seo et al, 2014). In our study, the rates of simultaneous seropositivity of HBsAg and anti-HBs in HBV infection patients were $3.0 \%$ and $1.4 \%$ in the cases and controls, respectively. Many studies have proved that patients with coexisting serological HBsAg and anti-HBs have more frequent mutations and variations in the antigenic epitopes of HBsAg that result in possible difficulty of virus clearance (Lada et al, 2006; Chen et al, 2011; Liu et al, 2012). In HBsAg-negative patients, anti-HBs was recognised as an antibody protecting from $\mathrm{HBV}$ infection. However, anti-HBs positive exhibited distinct clinical value in the subgroup with and without current HBV infection. Thus, to explore the value of antiHBs in GC, patients should be categorised into two subgroups. In Table 2, the univariated analyses showed that anti-HBs was related with GC when patients were analysed as a whole, but no relationship was found when patients were stratified into two subgroups. This could be explained as follows. Because the coexistence of HBsAg and anti-HBs was rare, and HBsAg was positively associated with GC, it was predictable that the cases had a lower rate of being anti-HBs positive. Thus, the negative association between anti-HBs and GC in the analysis of general patients actually reflected the positive association between HBsAg and GC.

Anti-HBc positive (combined with anti-HBs positive or not) was found to be associated with increased risks of liver and pancreatic cancer compared with those never exposed to HBV infection (Brechot et al, 2001; Hassan et al, 2008). Occult HBV infection, which indicated the presence of HBV DNA in the serum 
or liver in people lacking HBsAg in the serum outside the acute window phase period, was recurrently identified in anti-HBc-positive patients (Allain, 2004). However, in HBsAgnegative patients with liver cancer, not only the HBsAg-negative/ anti-HBc-positive/anti-HBs-negative and HBsAg-negative/anti$\mathrm{HBc}$-positive/anti-HBs-positive patients, but also HBsAg-negative/HBcAb-negative/HBsAb-negative patients were found to have HBV DNA detected (Paterlini et al, 1990). Being anti-HBc positive

Table 5. The subgroup analyses for patients with HBsAg negative multivariate logistic regression analyses

\begin{tabular}{|c|c|c|c|}
\hline Variable & AOR & $95 \% \mathrm{Cl}$ & $P$-value \\
\hline HBsAg negative (A) & & & 0.04 \\
\hline $\begin{array}{l}\text { HBsAg negative and anti-HBc negative } \\
\text { and anti-HBs negative }\end{array}$ & 1 & Reference & \\
\hline $\begin{array}{l}\text { HBsAg negative and anti-HBc negative } \\
\text { and anti-HBs positive }\end{array}$ & 1.04 & $0.74-1.45$ & 0.83 \\
\hline $\begin{array}{l}\text { HBsAg negative and anti-HBc positive } \\
\text { and anti-HBs negative }\end{array}$ & 1.67 & $0.997-2.80$ & 0.051 \\
\hline $\begin{array}{l}\text { HBsAg negative and anti-HBc positive } \\
\text { and anti-HBs positive }\end{array}$ & 0.79 & $0.533-1.17$ & 0.23 \\
\hline HBsAg negative (B) & & & 0.04 \\
\hline $\begin{array}{l}\text { HBsAg negative and anti-HBc positive } \\
\text { and anti-HBs negative }\end{array}$ & 1 & Reference & \\
\hline $\begin{array}{l}\text { HBsAg negative and anti-HBc negative } \\
\text { and anti-HBs positive }\end{array}$ & 0.62 & $0.39-0.996$ & 0.048 \\
\hline $\begin{array}{l}\text { HBsAg negative and anti-HBc positive } \\
\text { and anti-HBs positive }\end{array}$ & 0.47 & $0.28-0.49$ & 0.004 \\
\hline $\begin{array}{l}\text { HBsAg negative and anti-HBc negative } \\
\text { and anti-HBs negative }\end{array}$ & 0.60 & $0.36-1.003$ & 0.051 \\
\hline
\end{tabular}

Abbreviations: anti-HBc=antibody to hepatitis $\mathrm{B}$ core antigen; anti-HBs=antibody to hepatitis $\mathrm{B}$ surface antigen; $\mathrm{Cl}=$ confidence interval; $\mathrm{HBsAg}=$ hepatitis $\mathrm{B}$ surface antigen; $\mathrm{OR}=$ odds ratio. The results were adjusted by history of chronic gastritis (no/yes), family history of gastric cancer (no/yes), age (as a continuous variable), sex (male/female) and year of diagnosis (2007/2008/2009). (with or without anti-HBe positive) without being anti-HBs positive in HBsAg-negative patients was usually called anti-HBc only. Anti-HBc only was frequently found to be associated with $\mathrm{HBV}$ infection in blood transfusion, although the possibility of $\mathrm{HBV}$ infection in HBsAg-negative/anti-HBc-positive/anti-HBspositive blood transfusion was lower (Mosley et al, 1995; Allain, 2004; Allain et al, 2013). It could be speculated that the rates of occult HBV infection in anti-HBc-only patients, HBsAg-negative/ anti-HBc-positive/anti-HBs-positive patients and HBsAg-negative/ anti-HBc-negative/anti-HBs-negative patients might be sequentially decreasing. These findings helped to understand the results by the analyses for HBsAg-negative subgroup in our study.

Blood type A was found to be associated with a higher risk of GC (Wang et al, 2012). It was also found to synergistically increase the risk of pancreatic cancer with HBV infection (Wang et al, 2012). In our study, although the univariate logistic regression analysis found no association of $\mathrm{ABO}$ blood group with GC, multivariate logistic regression analysis showed that blood type $\mathrm{A}$ had a trend to be positively associated with GC compared with blood type $\mathrm{O}$ after adjustment by risk and potential confounding factors (AOR (95\% CI): $1.30(0.97-1.74), P=0.08$, Supplementary Table 5). Moreover, we found that blood type A also had some synergistic effects with HBV infection in GC (Table 6). Additional blood type A increased the risk for GC in HBsAg-positive patients, with AOR increasing from 1.49 to 2.41. Such a synergism was also found in pancreatic cancer (Wang et al, 2012) and extrahepatic cholangiocarcinoma (Zhou et al, 2013). However, the mechanism behind that has not been illuminated. Kai et al (2012) found that $\mathrm{HCV}$ infection was associated with GC in patients with liver cancer. There were some limitations in that study such as they did not include possible occult $\mathrm{HBV}$ coinfection as well as liver cirrhosis in the analyses. It was reported that the incidence of occult HBV infection was high in patients with HCV infection, and might increase the risk of liver cancer (Cardoso et al, 2013; Squadrito et al, 2013). In our study, the incidence of HCV was too low to identify any difference, and to investigate the aetiologic effect of HCV in GC in China, a larger case-control study or prospective study would be more convincing.

This was a well-matched case-control study, but some limitations should not be neglected. The most important one was the lack of information about $\mathrm{Hp}$ infection in the controls, and

Table 6. Univariate and multivariate logistic regression analyses for the synergistic effect of blood type A and HBV infection in gastric cancer

Univariate analyses

Multivariate analyses

\begin{tabular}{|c|c|c|c|c|c|c|}
\hline Variable & OR & $95 \% \mathrm{Cl}$ & $P$-value & AOR & $95 \% \mathrm{Cl}$ & $P$-value \\
\hline ABO blood group and $\mathrm{HBsAg}$ & & & 0.04 & & & 0.03 \\
\hline Blood type non-A and HBsAg negative & 1 & Reference & & 1 & Reference & \\
\hline Blood type $\mathrm{A}$ and $\mathrm{HBsAg}$ negative & 1.15 & $0.86-1.52$ & 0.35 & 1.20 & $0.90-1.60$ & 0.22 \\
\hline Blood type non-A and $\mathrm{HBsAg}$ positive & 1.42 & $0.96-2.09$ & 0.08 & 1.35 & $0.90-2.03$ & 0.15 \\
\hline Blood type $\mathrm{A}$ and $\mathrm{HBsAg}$ positive & 2.17 & $1.17-4.04$ & 0.02 & 2.41 & $1.28-4.53$ & 0.01 \\
\hline $\mathrm{ABO}$ blood group and anti-HBC & & & 0.26 & & & 0.13 \\
\hline Blood type non-A and anti-HBc negative & 1 & Reference & & 1 & Reference & \\
\hline Blood type $\mathrm{A}$ and anti-HBc negative & 1.09 & $0.78-1.53$ & 0.60 & 1.12 & $0.79-1.58$ & 0.54 \\
\hline Blood type non-A and anti-HBc positive & 1.10 & $0.83-1.45$ & 0.50 & 1.07 & $0.80-1.42$ & 0.66 \\
\hline Blood type $\mathrm{A}$ and anti-HBc positive & 1.49 & $1.01-2.20$ & 0.046 & 1.62 & $1.09-2.42$ & 0.02 \\
\hline
\end{tabular}


thus the associations of $\mathrm{HBV}$ and GC were not adjusted by $\mathrm{Hp}$ infection. To make up for this flaw, we analysed the association of anti-HBs (positive/negative) and HBsAg (positive/negative) with $\mathrm{Hp}$ (positive/negative). No association was found (Supplementary Table 6). In addition, some previous studies also suggested $\mathrm{Hp}$ infection was not related with HBV infection in gastric mucosa. Chen et al (2004) reported that there was no difference in the expression of $\mathrm{HBV}$ antigens in the $\mathrm{Hp}$-positive and -negative gastric antrum mucosa in patients with HBV infection. Another study by Kirchner et al (2011) revealed that the association of $\mathrm{Hp}$ infection with gastric ulcers was weak in liver cirrhosis patients, suggesting the existence of other important aetiologic factors for ulcers in this population. From the above studies, although we did not include $\mathrm{Hp}$ infection in logistic regression analyses, some proofs supported the lack of interaction between HBV and Hp infection. More qualified case-control studies with the information of $\mathrm{Hp}$ infection status included are needed in future. In addition, we failed to choose healthy people as the controls, and the heterogeneity of patients with various kinds of benign diseases might have some influences in our study. In addition, we could not analyse the role of liver cirrhosis and changes of liver function as well as subsequent changes in life style in GC owning to lack of relevant data in our study. Moreover, this study was retrospectively conducted, and thus its efficacy to test a risk factor in the aspect of direct causal relationship was relatively weak. The association of $\mathrm{HBV}$ infection with the risk of GC needs to be confirmed in future prospective study.

In conclusion, this case-control study is the first one to discover the association between HBV infection and GC. Gastric cancer was found to be associated with a significantly higher rate of positive $\mathrm{HBsAg}$, indicating $\mathrm{HBV}$ infection may be a possible risk factor for GC. Occult HBV infection and synergistic effects of HBV infection with blood type A were also found to have some roles in the risk of GC. Future studies need to verify the existence of HBV DNA and antigens in GC, and large-scale prospective investigations are warranted to testify the conclusions, and the mechanisms need to be more specifically and thoroughly investigated.

\section{ACKNOWLEDGEMENTS}

This work was supported by National High Technology Research and Development Program of China (863 Program), China (No. 2012AA02A506), National Natural Science Foundation of China (No. 81372570), The Science and Technology Department of Guangdong Province, China (No. 2012B031800088) and The Science and Technology Department of Guangdong Province, China (No. C2011019). We gratefully thank Ying Guo in the Epidemiology Department for her suggestion in the statistical analysis. In addition, we thank the staff members of the Department of Medical Oncology at Sun Yat-sen University Cancer Center for their assistance and suggestion.

\section{CONFLICT OF INTEREST}

The authors declare no conflict of interest.

\section{AUTHOR CONTRIBUTIONS}

In the initial phase of this study, RHX, XLW and YHL designed the study. XLW, MZQ, YXH and RYW participated in the clinical data collection of both cases and controls. DSW, FW and HYL participated in the collection of information on hepatitis B virus infection and Helicobacter pylori infection. YJ, WWC and DSZ performed the statistical analysis. XLW drafted the manuscript. MZQ, YJ and FHW revised the manuscript. RHX coordinated work and helped to draft and revise the manuscript. All authors read and approved the final manuscript.

After we received the request for revision of our manuscript, XLW, YJ and DSZ participated in the collection of supplementary information needed to revise the manuscript and answer the questions of reviewers, such as the diagnoses of non-malignant diseases, the information of liver function and liver cirrhosis. XLW and DSZ wrote the rebuttal letter and revised the manuscript. RHX helped to revise the manuscript. The revised manuscript was read and approved by all authors.

Explanation for the designation of co-first authors: In the initial phase of this study, XLW, MZQ and YJ had main contributions, so they were designed as co-first authors when we submitted the manuscript. However, in the revision phase of the study, the contribution of DSZ made us reconsider his author order. All the authors agreed that DSZ should also be listed as a co-first author.

\section{REFERENCES}

Allain JP (2004) Occult hepatitis B virus infection. Transfus Clin Biol 11: $18-25$.

Allain JP, Mihaljevic I, Gonzalez-Fraile MI, Gubbe K, Holm-Harritshoj L, Garcia JM, Brojer E, Erikstrup C, Saniewski M, Wernish L, Bianco L, Ullum H, Candotti D, Lelie N, Gerlich WH, Chudy M (2013) Infectivity of blood products from donors with occult hepatitis $\mathrm{B}$ virus infection. Transfusion 53: 1405-1415.

Arzumanyan A, Reis HM, Feitelson MA (2013) Pathogenic mechanisms in $\mathrm{HBV}$ - and HCV-associated hepatocellular carcinoma. Nat Rev Cancer 13: 123-135.

Brechot C, Thiers V, Kremsdorf D, Nalpas B, Pol S, Paterlini-Brechot P (2001) Persistent hepatitis B virus infection in subjects without hepatitis B surface antigen: clinically significant or purely 'occult'? Hepatology 34: 194-203.

Cardoso C, Alves AL, Augusto F, Freire R, Quintana C, Goncalves M, Oliveira AP (2013) Occult hepatitis B infection in Portuguese patients with chronic hepatitis $\mathrm{C}$ liver disease: prevalence and clinical significance. Eur J Gastroenterol Hepatol 25: 142-146.

Chen CJ, Yang HI, Su J, Jen CL, You SL, Lu SN, Huang GT, Iloeje UH (2006) Risk of hepatocellular carcinoma across a biological gradient of serum hepatitis B virus DNA level. JAMA 295: 65-73.

Chen NL, Bai L, Deng T, Zhang C, Kong QY, Chen H (2004) Expression of hepatitis $\mathrm{B}$ virus antigen and Helicobacter pylori infection in gastric mucosa of patients with chronic liver disease. Hepatobiliary Pancreat Dis Int 3: 223-225.

Chen Y, Qian F, Yuan Q, Li X, Wu W, Guo X, Li L (2011) Mutations in hepatitis B virus DNA from patients with coexisting HBsAg and anti-HBs. J Clin Virol 52: 198-203.

Correa P, Fox J, Fontham E, Ruiz B, Lin YP, Zavala D, Taylor N, Mackinley D, de Lima E, Portilla H (1990) Helicobacter pylori and gastric carcinoma. Serum antibody prevalence in populations with contrasting cancer risks. Cancer 66: 2569-2574.

Dehesa-Violante M, Nunez-Nateras R (2007) Epidemiology of hepatitis virus B and C. Arch Med Res 38: 606-611.

Dejean A, Lugassy C, Zafrani S, Tiollais P, Brechot C (1984) Detection of hepatitis B virus DNA in pancreas, kidney and skin of two human carriers of the virus. J Gen Virol 65(Pt 3): 651-655.

Engels EA, Cho ER, Jee SH (2010) Hepatitis B virus infection and risk of non-Hodgkin lymphoma in South Korea: a cohort study. Lancet Oncol 11: 827-834.

Gonzalez CA, Sala N, Capella G (2002) Genetic susceptibility and gastric cancer risk. Int J Cancer 100: 249-260.

Hassan MM, Li D, El-Deeb AS, Wolff RA, Bondy ML, Davila M, Abbruzzese JL (2008) Association between hepatitis B virus and pancreatic cancer. J Clin Oncol 26: 4557-4562.

Jemal A, Bray F, Center MM, Ferlay J, Ward E, Forman D (2011) Global cancer statistics. CA Cancer J Clin 61: 69-90.

Kai K, Miyoshi A, Kitahara K, Masuda M, Takase Y, Miyazaki K, Noshiro H, Tokunaga O (2012) Analysis of extrahepatic multiple primary 
malignancies in patients with hepatocellular carcinoma according to viral infection status. Int J Hepatol 2012: 495950.

Kim Y, Shin A, Gwack J, Ko KP, Kim CS, Park SK, Hong YC, Kang D, Yoo KY (2009) Epstein-Barr virus antibody level and gastric cancer risk in Korea: a nested case-control study. Br J Cancer 101: 526-529.

Kirchner GI, Beil W, Bleck JS, Manns MP, Wagner S (2011) Prevalence of Helicobacter pylori and occurrence of gastroduodenal lesions in patients with liver cirrhosis. Int J Clin Exp Med 4: 26-31.

Lada O, Benhamou Y, Poynard T, Thibault V (2006) Coexistence of hepatitis B surface antigen ( $\mathrm{HBs} \mathrm{Ag}$ ) and anti-HBs antibodies in chronic hepatitis B virus carriers: influence of 'a' determinant variants. J Virol 80: 2968-2975.

Ladeiras-Lopes R, Pereira AK, Nogueira A, Pinheiro-Torres T, Pinto I, Santos-Pereira R, Lunet N (2008) Smoking and gastric cancer: systematic review and meta-analysis of cohort studies. Cancer Causes Control 19: 689-701.

Lee MH, Yang HI, Liu J, Batrla-Utermann R, Jen CL, Iloeje UH, Lu SN, You SL, Wang LY, Chen CJ (2013a) Prediction models of long-term cirrhosis and hepatocellular carcinoma risk in chronic hepatitis B patients: risk scores integrating host and virus profiles. Hepatology 58: 546-554.

Lee MH, Yang HI, Liu J, Batrla-Utermann R, Jen CL, Iloeje UH, Lu SN, You SL, Wang LY, Chen CJ (2013b) Prediction models of long-term cirrhosis and hepatocellular carcinoma risk in chronic hepatitis B patients: risk scores integrating host and virus profiles. Hepatology 58: 546-554.

Liu W, Hu T, Wang X, Chen Y, Huang M, Yuan C, Guan M (2012) Coexistence of hepatitis B surface antigen and anti-HBs in Chinese chronic hepatitis $\mathrm{B}$ virus patients relating to genotype $\mathrm{C}$ and mutations in the $S$ and $P$ gene reverse transcriptase region. Arch Virol 157: 627-634.

Loh M, Koh KX, Yeo BH, Song CM, Chia KS, Zhu F, Yeoh KG, Hill J, Iacopetta B, Soong R (2009) Meta-analysis of genetic polymorphisms and gastric cancer risk: variability in associations according to race. Eur J Cancer 45: 2562-2568.

Lu FM, Li T, Liu S, Zhuang H (2010) Epidemiology and prevention of hepatitis B virus infection in China. J Viral Hepat 17(Suppl 1): 4-9.

Mason A, Wick M, White H, Perrillo R (1993) Hepatitis B virus replication in diverse cell types during chronic hepatitis B virus infection. Hepatology 18: 781-789.

Mosley JW, Stevens CE, Aach RD, Hollinger FB, Mimms LT, Solomon LR, Barbosa LH, Nemo GJ (1995) Donor screening for antibody to hepatitis B core antigen and hepatitis $\mathrm{B}$ virus infection in transfusion recipients. Transfusion 35: 5-12.

Niwa T, Tsukamoto T, Toyoda T, Mori A, Tanaka H, Maekita T, Ichinose M, Tatematsu M, Ushijima T (2010) Inflammatory processes triggered by Helicobacter pylori infection cause aberrant DNA methylation in gastric epithelial cells. Cancer Res 70: 1430-1440.

Norat T, Aune D, Chan D, Romaguera D (2014) Fruits and Vegetables: updating the epidemiologic evidence for the WCRF/AICR lifestyle recommendations for cancer prevention. Cancer Treat Res 159: 35-50.

Paterlini P, Gerken G, Nakajima E, Terre S, D’Errico A, Grigioni W, Nalpas B, Franco D, Wands J, Kew M, Pisi E, Tiollais P, Brechot C (1990) Polymerase chain reaction to detect hepatitis B virus DNA and RNA sequences in primary liver cancers from patients negative for hepatitis B surface antigen. N Engl J Med 323: 80-85.

Peleteiro B, Lopes C, Figueiredo C, Lunet N (2011) Salt intake and gastric cancer risk according to Helicobacter pylori infection, smoking, tumour site and histological type. Br J Cancer 104: 198-207.

Sadjadi A, Derakhshan MH, Yazdanbod A, Boreiri M, Parsaeian M, Babaei M, Alimohammadian M, Samadi F, Etemadi A, Pourfarzi F, Ahmadi E, Delavari A, Islami F, Farzadfar F, Sotoudeh M, Nikmanesh A, Alizadeh BZ, de Bock GH, Malekzadeh R (2014) Neglected role of hookah and opium in gastric carcinogenesis: A cohort study on risk factors and attributable fractions. Int J Cancer 134: 181-188.

Seo SI, Choi HS, Choi BY, Kim HS, Kim HY, Jang MK (2014) Coexistence of hepatitis B surface antigen and antibody to hepatitis B surface may increase the risk of hepatocellular carcinoma in chronic hepatitis B virus infection: a retrospective cohort study. J Med Virol 86(1): 124-130.

Shakeri R, Malekzadeh R, Etemadi A, Nasrollahzadeh D, Aghcheli K, Sotoudeh M, Islami F, Pourshams A, Pawlita M, Boffetta P, Dawsey SM, Abnet CC, Kamangar F (2013) Opium: an emerging risk factor for gastric adenocarcinoma. Int J Cancer 133: 455-461.

Squadrito G, Cacciola I, Alibrandi A, Pollicino T, Raimondo G (2013) Impact of occult hepatitis B virus infection on the outcome of chronic hepatitis $\mathrm{C}$. J Hepatol 59: 696-700.

Tan YJ (2011) Hepatitis B virus infection and the risk of hepatocellular carcinoma. World J Gastroenterol 17: 4853-4857.

Tian Y, Yang W, Song J, Wu Y, Ni B (2013) Hepatitis B virus $\mathrm{X}$ protein-induced aberrant epigenetic modifications contributing to human hepatocellular carcinoma pathogenesis. Mol Cell Biol 33: 2810-2816.

Tramacere I, Negri E, Pelucchi C, Bagnardi V, Rota M, Scotti L, Islami F, Corrao G, La Vecchia C, Boffetta P (2012) A meta-analysis on alcohol drinking and gastric cancer risk. Ann Oncol 23: 28-36.

Wang DS, Chen DL, Ren C, Wang ZQ, Qiu MZ, Luo HY, Zhang DS, Wang FH, Li YH, Xu RH (2012) ABO blood group, hepatitis B viral infection and risk of pancreatic cancer. Int J Cancer 131: 461-468.

Wang Z, Liu L, Ji J, Zhang J, Yan M, Zhang J, Liu B, Zhu Z, Yu Y (2012) $\mathrm{ABO}$ blood group system and gastric cancer: a case-control study and meta-analysis. Int J Mol Sci 13: 13308-13321.

Yaghoobi M, Bijarchi R, Narod SA (2010) Family history and the risk of gastric cancer. Br J Cancer 102: 237-242.

Yoon JM, Son KY, Eom CS, Durrance D, Park SM (2013) Pre-existing diabetes mellitus increases the risk of gastric cancer: a meta-analysis. World J Gastroenterol 19: 936-945.

Yu MC, Tong MJ, Coursaget P, Ross RK, Govindarajan S, Henderson BE (1990) Prevalence of hepatitis B and C viral markers in black and white patients with hepatocellular carcinoma in the United States. J Natl Cancer Inst 82: 1038-1041.

Yuan XY, Wang MY, Wang XY, Chang AY, Li J (2013) Non-detection of Epstein-Barr virus and Human Papillomavirus in a region of high gastric cancer risk indicates a lack of a role for these viruses in gastric carcinomas. Genet Mol Biol 36: 183-184.

Zhang JM, Xu Y, Wang XY, Yin YK, Wu XH, Weng XH, Lu M (2007) Coexistence of hepatitis B surface antigen (HBsAg) and heterologous subtype-specific antibodies to HBsAg among patients with chronic hepatitis B virus infection. Clin Infect Dis 44: 1161-1169.

Zhou Y, Zhou Q, Lin Q, Chen R, Gong Y, Liu Y, Yu M, Zeng B, Li K, Chen R, Li Z (2013) Evaluation of risk factors for extrahepatic cholangiocarcinoma: $\mathrm{ABO}$ blood group, hepatitis B virus and their synergism. Int $J$ Cancer 133: $1867-1875$.

Zullo A, Romiti A, Tomao S, Hassan C, Rinaldi V, Giustini M, Morini S, Taggi F (2003) Gastric cancer prevalence in patients with liver cirrhosis. Eur J Cancer Prev 12: 179-182.

This work is published under the standard license to publish agreement. After 12 months the work will become freely available and the license terms will switch to a Creative Commons AttributionNonCommercial-Share Alike 4.0 Unported License.

Supplementary Information accompanies this paper on British Journal of Cancer website (http://www.nature.com/bjc) 